Journal of Accident and Emergency Medicine 1995 12, 225-226

\title{
Broken hand or broken nose: a case report
}

\author{
B.P. SHRAVAT \& S.N. HARROP
}

Department of Accident and Emergency Medicine, Blackpool Victoria Hospital NHS Trust, Blackpool, UK

\section{SUMMARY}

We report an unusual case of a foreign body in the hand, following a type of injury commonly encountered in the accident and emergency (A\&E) department.

Keywords: foreign body, infection metacarpophlangeal joint.

\section{CASE REPORT}

A 14-year-old boy presented to the A\&E department with an injury to the right hand after he had punched someone in the face. There was swelling, tenderness and a small puncture wound on the dorsum of the metacarpophalangeal joint of the little finger. Radiographs of the hand showed fracture of the neck of the metacarpal of the little finger (Fig. 1).

The wound was treated as a compound fracture and healed with residual swelling and tenderness. Five weeks after injury the patient returned to the A\&E department with a discharging wound. Close

\section{Correspondence:}

B. P. Shravat, Staff Surgeon, Department of Accident and Emergency Medicine, Blackpool Victoria Hospital NHS Trust, Whinney Heys Road, Blackpool FY3 8NR, UK
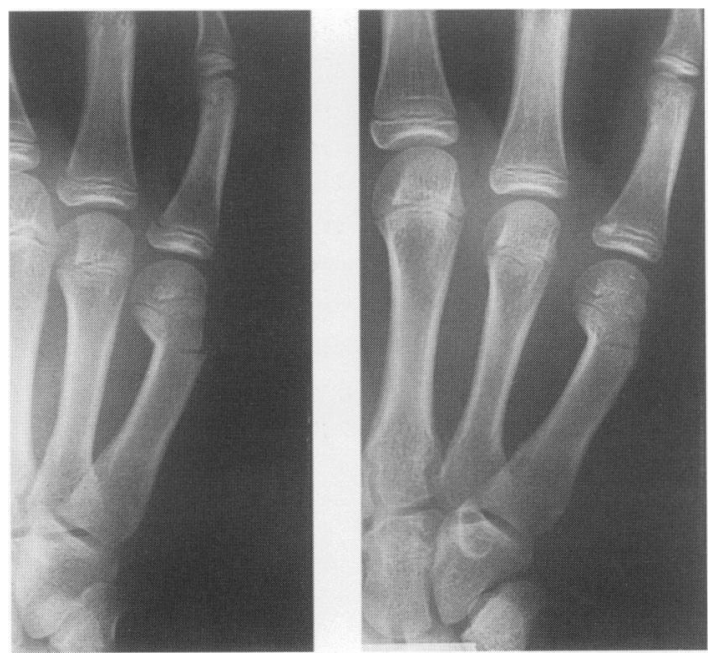

Fig. 1. Original postero-anterior and oblique radiograph of the patient's hand.

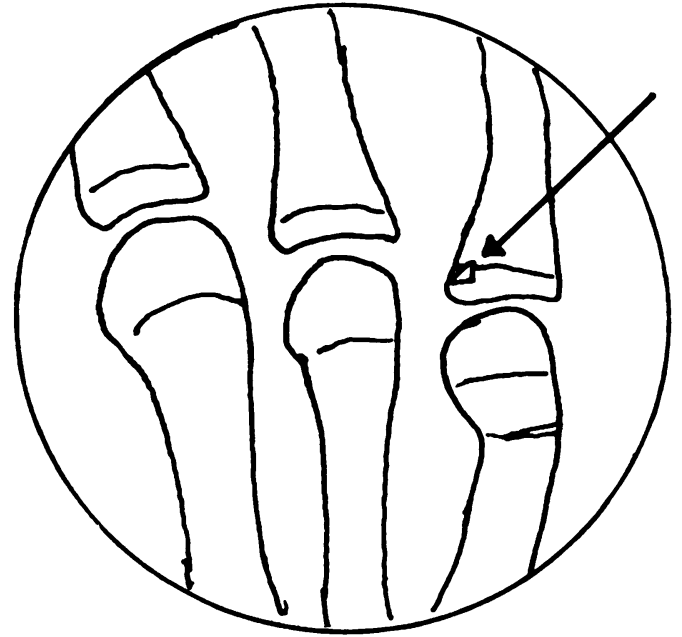

Fig. 2. Line drawing of original radiographs demonstrating the fracture diagnosed and the small opacity that escaped notice.

inspection and palpation of the discharging wound revealed a small white mass, visible and palpable through the healed skin. Review of the original radiographs revealed a small triangular opacity $(2 \times$ $2 \times 3 \mathrm{~mm}$ ) of low density, superimposed on the epiphysis at the base of the proximal phalanx (Fig. 2). No bone defect was evident to indicate the precise origin of the fragment.

The wound was explored and a piece of bone was removed (Figs 3 and 4). The patient then remembered that he had broken the person's nose when he had punched him. The victim's case notes were retrieved, and these confirmed a wound, approximately $1 \mathrm{~cm}$ in length, across the bridge of the nose.

\section{DISCUSSION}

The victim's wound offers a source for the bony fragment, whose origin cannot be accounted for by the nature of the assailant's fracture. We conclude that the material removed from the assailant's hand was extrinsic, criginating in the victim's nasal bone. Although all our A\&E 

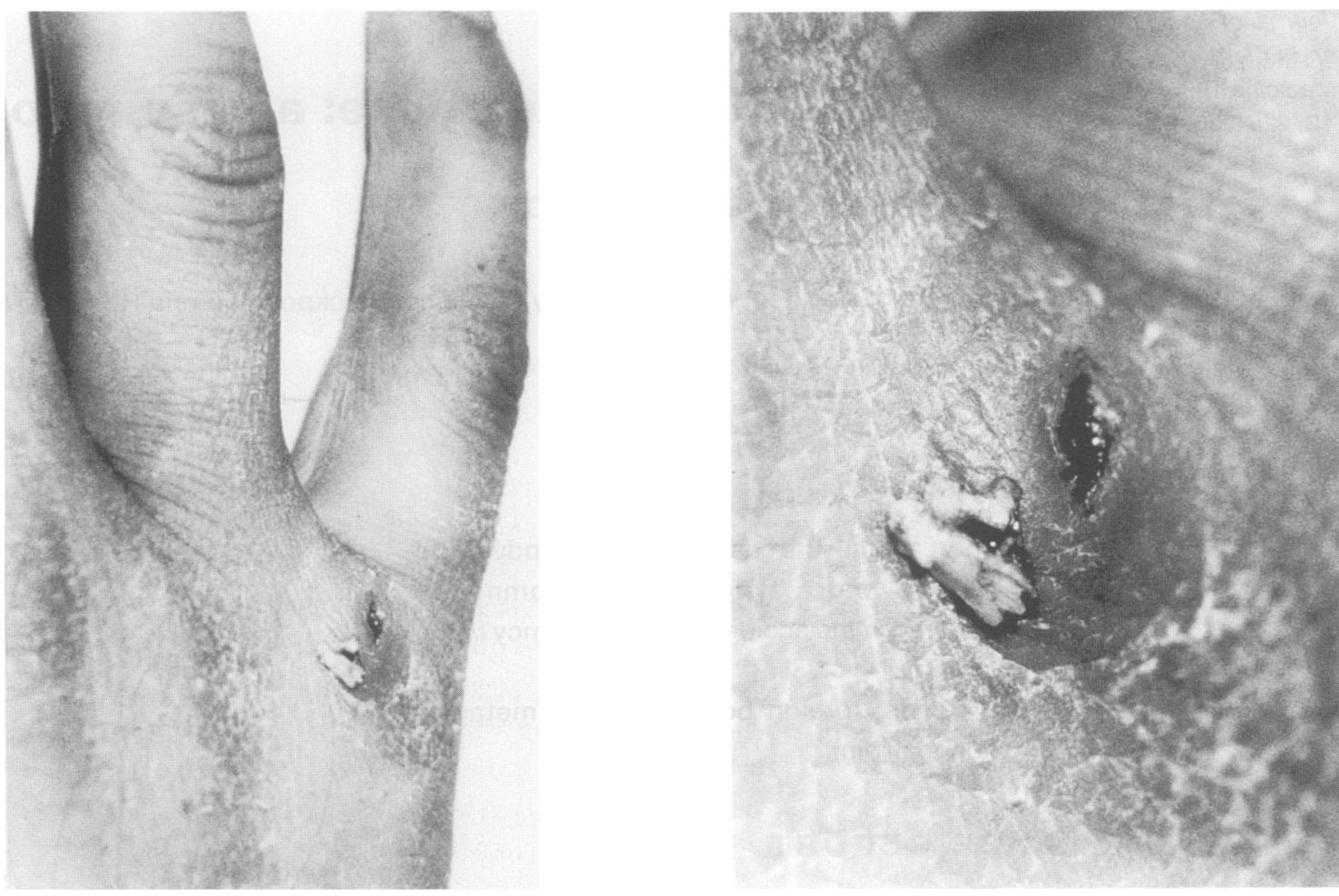

Figs 3 and 4. The piece of nasal bone removed from the wound.

radiographs are reported subsequent to initial attendance by a consultant radiologist, the extraneous bone fragment shown on this film escaped initial notice.

'Hand to mouth' injuries are often missed or underestimated. Retained fragments of teeth in such injuries have been reported. A case has been reported of a broken half of an incisor tooth inside the head of third metacarpal bone which remained undetected for 17 months, despite repeatedly breaking down to form a discharging sinus.'

\section{REFERENCES}

1. Parkington T.R. \& Tayton K.J.J. (1980) Unusual case of gnawing pain in the hand. British Medical Joumal, 281, 1683. 